\title{
Directly immobilized DNA sensor for label-free detection of herpes virus
}

\author{
Phuong Dinh Tam ${ }^{1,2}$, Mai Anh Tuan², Nguyen Duc Chien ${ }^{3}$

\begin{abstract}
${ }^{1}$ Hanoi Advanced School of Science and Technology, Hanoi University of Technology, Hanoi, Vietnam; ${ }^{2}$ International Training Institute for Materials Science, Hanoi University of Technology, Hanoi, Vietnam; ${ }^{3}$ Institute of Engineering Physics, Hanoi University of Technology, Hanoi, Vietnam.

Email: tampd-hast@mail.hut.edu.vn
\end{abstract}

Received 24 March 2008; revised 12 May 2009; accepted 29 June 2009.

\begin{abstract}
This paper reports the direct immobilization of deoxyribonucleic acid (DNA) sequences of Herpes simplex virus (5'-AT CAC CGA CCC GGA GAG GGA C-3') on the surface of DNA sensor by using the cyclic voltammetric method with the presence of pyrrole. The potential was scanned from -0.7 volt to +0.6 volt, the scanning rate was at $100 \mathrm{mV} / \mathrm{s}$. This kind of DNA sensor was developed to detect Herpes virus DNA in real samples. The FTIR was applied to verify specific binding of DNA sequence and conducting polymer, the morphology of conducting polymer doped with DNA strands was investigated by using a field emission scanning electron microscope (FE-SEM). The results showed that output signal given by co-immobilized DNA/PPy membrane sensor was better than that given by APTS immobilized membrane sensors. The sensor can detect as low as 2 nM of DNA target in real samples.
\end{abstract}

Keywords: DNA Sensor; Hybridization; APTS

\section{INTRODUCTION}

The detection of specific DNA/RNA sequences is of great importance in numerous applications of modern life science, including identification of medical research and clinical diagnosis $[1,2]$, controlling the food quality $[3,4]$, environmental analysis [5,6]. Many methods have been used for this purpose such as polymerase chain reaction (PCR) [7,8,9], quartz crystal micro-balance (QCM) [10,11], fluorescence [12], surface plasmon resonance [13], microfluidic system [14], cell culture and real-time PCR, etc. These methods are precise, and allow a wide, dynamic range of detection. However, they are complex, costly and time consuming. In addition, it is impossible to carry the on-site/in-field tests. Thus, development of a cheap, reliable device allowing rapid detection is always the challenge for scientists and engineers. In this context, DNA sensor based on electrochemical detection is one of the feasible and promising tools.

We reported, in this paper, the direct co-immobilization of DNA sequence of Herpes simplex virus and polypyrrole onto the surface of a sensor by cyclic voltammetry to determine the herpes DNA target sequence in the sample. The herpes simplex virus (HSV) is an enveloped double-stranded DNA virus. There are two distinct forms of HSV, serotype 1 and serotype 2 (HSV1 and HSV-2). HSV-2 is the most common cause of genital herpes, whereas HSV-1 is the most common cause of facial herpes or cold scores. HSV-1 is transmitted through contact with oral secretions. Diseases caused by Herpes virus are commonly found in patients in Vietnam.

\section{EXPERIMENTS}

\subsection{Chemical Reagents}

DNA sequences used in this work (Table 1) were supplied by Invitrogen Life Technologies Company through National Institute of Hygiene and Epidemiology of Vietnam. Pyrrole was purchased from Merck. Other chemicals are of analytical grade.

\subsection{Sensor Fabrication}

The microelectrode based DNA sensor was designed and fabricated at clean room of ITIMS. The sensor consists of pairs of microelectrodes on the surface of silicon substrate, one of which acts as working sensor and the other as a reference electrode. The dimension of the interelectrodes was $20 \mu \mathrm{m}$ x $20 \mu \mathrm{m}$ (Figure 1). The detailed fabrication process was discussed in [15].

\subsection{Cyclic Volttametry Electropolymerization}

Electropolymerization was carried out by using IM6EX 
Table 1. DNA sequences used in this work.

\begin{tabular}{|c|c|}
\hline Types & DNA sequences \\
\hline Probe & 5'-AT CAC CGA CCC GGA GAG GGA C-3' \\
\hline Non-complementary & 5'-AT CAC CGA CCC GGA GAG GGA C-3, \\
\hline Target & 3'-TA GTG GCT GGG CCT CTC CCT G-5' \\
\hline $\mathrm{Mis} / 1$ & 3'-TA GTG G $\underline{G}$ T GGG CCT CTC CCT G-5' \\
\hline $\mathrm{Mis} / 2$ & 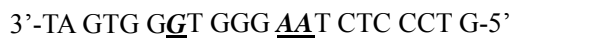 \\
\hline
\end{tabular}

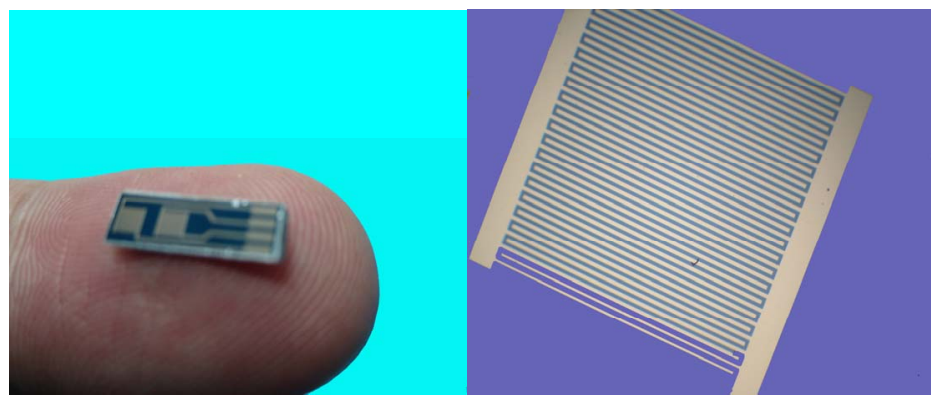

Figure 1. $20 \mu \mathrm{m}$ x $20 \mu \mathrm{m}$ microelectrode sensor was fabricated at ITIMS.

(Germany) impedance analyzer at room temperature in which the micro-sensor acted as working electrode while auxiliary electrode was a platinum wire. Reference electrode is $\mathrm{Ag} / \mathrm{AgCl}$ in saturated $\mathrm{KCl}$.

The sensor was first surface cleaned by $\mathrm{KCr}_{2} \mathrm{O}_{7}$ in $\mathrm{H}_{2} \mathrm{SO}_{4} 98 \%$ followed by cyclic voltammograms (swept potential from $-1.5 \mathrm{~V}$ to $+2.1 \mathrm{~V}$, scan rate: $25 \mathrm{mV} / \mathrm{s}$ ) in $0.5 \mathrm{M} \mathrm{H}_{2} \mathrm{SO}_{4}$ to activate the surface of the sensors. Finally, the potential was swept on the working electrode from -0.7 volt to 0.6 volt versus standard counter electrode (SCE). The scanning rate was $100 \mathrm{mV} / \mathrm{s}$.

\subsection{Measurement}

Differential measurements were realized to determine the changes in conductance of DNA membrane. An AC reference signals $(10 \mathrm{KHz}, 100 \mathrm{mV}$ sine wave), generated by the generator of Lock-in Amplifier SR830, and was applied on two identical micro-electrodes of DNA sensor. The output signal was acquired by measuring the voltage drop on two $1 \mathrm{~K} \Omega$ resistances by the $\mathrm{A}$ and $\mathrm{B}$ channels of the Lock-in Amplifier and processed by a PC through RS 232 interface. All measurements were performed at room temperature. In this experiment, five DNA sensors were used to test the hybridization of DNA sequences.

\section{RESULTS AND DISCUSSION}

\subsection{The Polymerization of PPy/DNA}

Normally, pyrrole is polymerized with the presence of an anionic dopant which contributes to film conductivity. Variety of anions can be used as dopant for polypyrrole
(Ppy) polymerization such as $\mathrm{Cl}^{-}, \mathrm{NO}_{3}^{-}$. In this work $\mathrm{ClO}_{4}{ }^{-}$and DNA sequence were used.

According to Wang et al [16], DNA can be considered as sole counter anion in the electropolymerization process at the working electrode. This allowed maximum possible incorporation of DNA in the conductive polymer throughout the film thickness and full contribution of oligonucleotides charged phosphates to the polymer conductivity.

The cyclic voltammograms of synthesized Ppy and Ppy/DNA film is shown in Figure 2 where the oxidation of pyrrole monomer leads to the formation of radical cation, subsequent oxidation of the dimer and coupling will result in the formation of an insoluble polymer, positively charged on the surface. This electrochemical procedure allowed the formation of a copolymer which

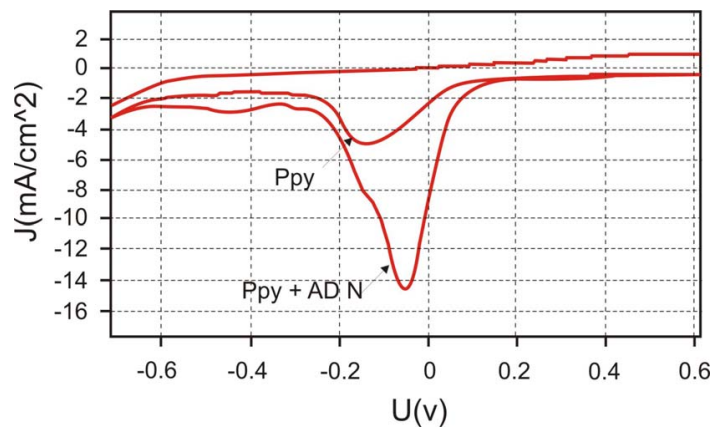

Figure 2. Cyclic voltammograms of $0.5 \mathrm{mM}$ Ppy doped $0.05 \mu \mathrm{M}$ DNA probe sequence in $\mathrm{LiClO}_{4}$ solution. Swept potential from $-0.7 \mathrm{~V}$ to $0.6 \mathrm{~V}$, scanning rate is at $100 \mathrm{mV} / \mathrm{s}$. 
is a mixture of polypyrrole and an oligonucleotides that shows an increasing current along with conducting film growth which corresponds to incorporation of oligo into the Ppy film. The film was rinsed and used for detection of DNA hybridization.

\subsection{FTIR Spectrum of Ppy and DNA/Ppy}

In this work, the FTIR spectroscopy was used to verify the existence of polypyrrole and DNA sequence on the microelectrode surface after the polymerization process. The infrared spectrum of the DNA/Ppy complexes and pure Ppy were performed on Niconet 6700 FT-IR machine with the effective range from $400 \mathrm{~cm}^{-1}$ to 4000 $\mathrm{cm}^{-1}$ at room temperature. As shown in Figure 3, the absorption band at $1889 \mathrm{~cm}^{-1}-1629 \mathrm{~cm}^{-1}$ vibration plane implied G-C and A-T base pairs while the backbone phosphate group at $1095 \mathrm{~cm}^{-1}$ was perturbed upon Ppy interaction $[17,18]$.

The absorption band at $1254 \mathrm{~cm}^{-1}$ was assigned to the biopolaronic species formed in the over oxidation pro- cess of Ppy [19]. The C-H and N-H bonds were also observed at $735 \mathrm{~cm}^{-1}$ (for DNA/Ppy film); $734 \mathrm{~cm}^{-1}$ for Ppy film; $894 \mathrm{~cm}^{-1}$ for DNA/Ppy and $897 \mathrm{~cm}^{-1}$ for Ppy membrane, respectively. These results show very good agree- ment with earlier reported work [20].

\subsection{Morphology of Conducting Polymer Film}

The morphology of sensor surface coated with Ppy film was studied by FE-SEM. Figure 4 indicated micrographs of polypyrrole doped with $\mathrm{LiClO} 4$ (4a) and with both $0.1 \mathrm{M} \mathrm{LiClO}_{4}$ and $0.05 \mu \mathrm{M}$ DNA sequence (4b) membrane given by direct electropolymerization method.

In Figure 4(a), the pure PPy doped with $\mathrm{LiClO}_{4}$ was cauli-flower structure matching other works [21]. This structure is related to the dopant intercalation in the polymeric chain. As in Figure 4(b) the DNA strands was observed as white dots in host polymer membrane. Good distribution of DNA in PPy membrane makes it advantage for hybridization process of the probe in target solution.

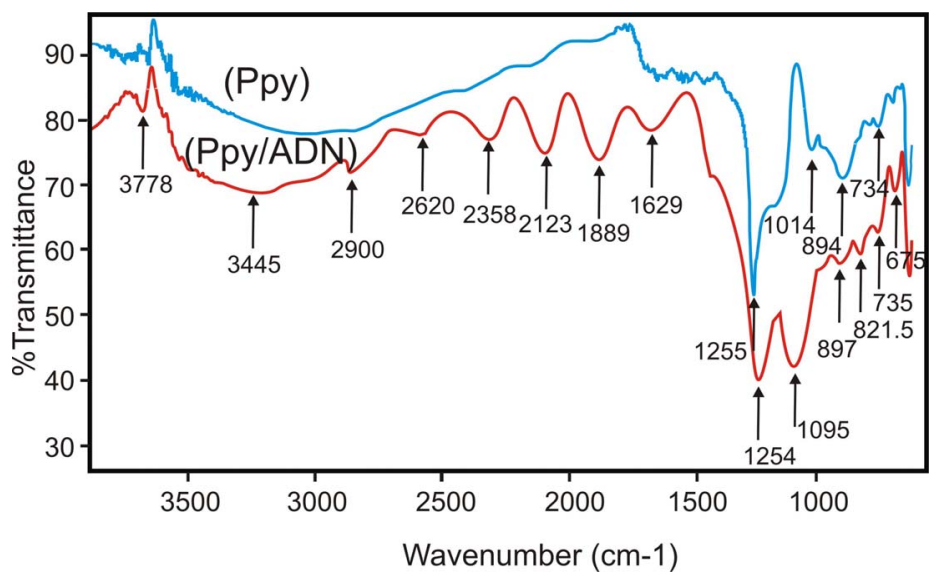

Figure 3. The FTIR spectra of Ppy/DNA and Ppy (upper curve: Ppy/dopant, lower curve: Ppy/dopant/DNA).

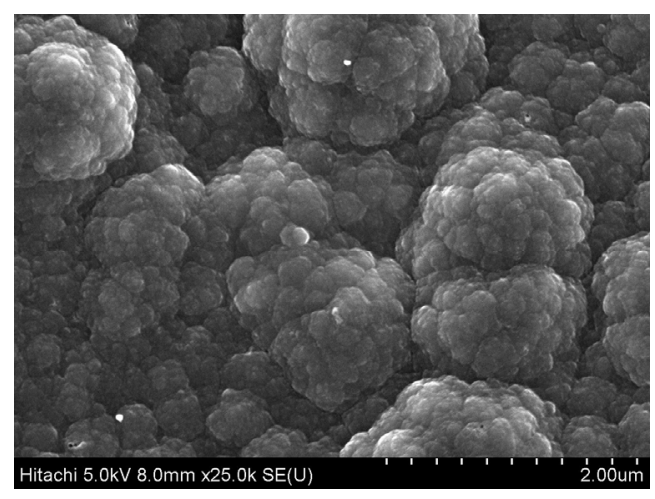

(a)

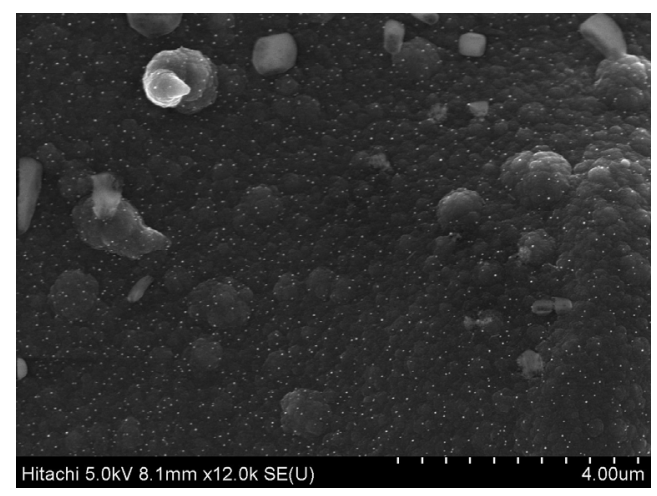

(b)

Figure 4. The FE-SEM of Ppy and Ppy-DNA coated onto microelectrode surface. a) Ppy doped Li$\mathrm{ClO}_{4}$; b) (C) Ppy doped $\mathrm{LiClO}_{4}$ and DNA. 


\subsection{The Hybridization of DNA Sensor}

As above-mentioned, the probe-attached sensor is commonly soaked into solution containing target DNA. A DNA helix sequence is formed on the surface of the sensor when target/immobilized DNA matching occurred.

Such hybridization is detected by changes in the conductance of the conductive membrane on the surface of sensors leading to the change in output signal of the system. In Figure 5, the hybridization illustrated by linear curve that described the relation between the target DNA concentration and output signal of the DNA sensor. For both APTS and Ppy/DNA attachment method, the sensor can detect as low as $2 \mathrm{nM}$ of target DNA. However, the intensity of the output signal found to be better when direct immobilization was used than that given by APTS. This is explained by the contribution of Ppy and dopant which improve the conductivity of the membrane namely enhancing the electric charge transfer within the film.

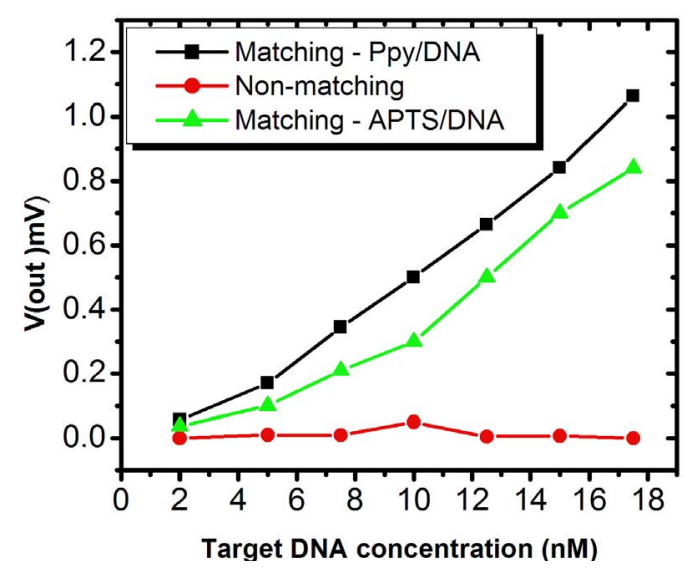

Figure 5. DNA sequence hybridization curve at room temperature, $0.05 \mu \mathrm{M}$ probe DNA.

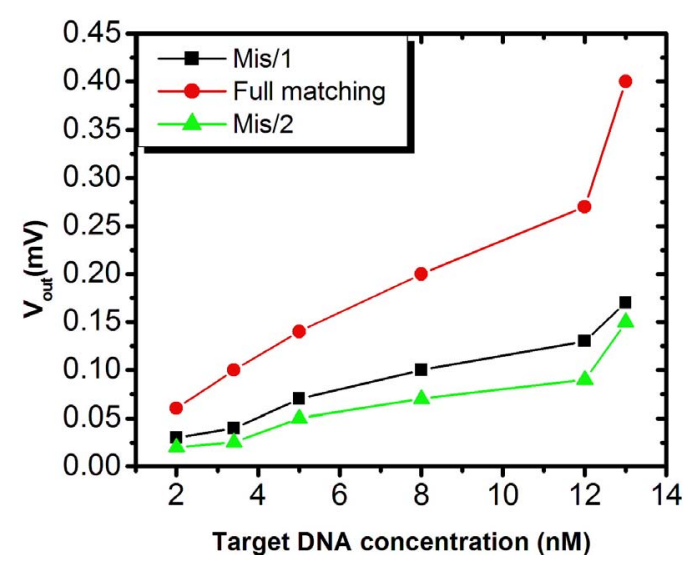

Figure 6. The detection mismatch DNA sequence at room temperature, $0.05 \mu \mathrm{M}$ probe DNA.

\subsection{Detection of Mismatches DNA Sequence Using the DNA Sensor}

Mismatch detection is our first trial step for sensor selectivity investigation. In this work, we used two different mismatched sequences of Herpes virus (Table 1), and then compared their hybridization signals with those of fully complementary targets to investigate the effects of the base pair mismatches. As presented in Figure 6, a much stronger signal of DNA hybridization containing fully matched DNA compares to system containing mismatched DNA was clearly found. This study is still in progress for statistic conclusion.

The influence of the mismatch positions was investigated by change of the DNA single base pair mismatch (mis/1) possessed a C (Cytosine) instead of a $\mathrm{G}$ (Guanine) at the $7^{\text {th }}$ oligo and the three base pair mismatch sequence (mis/2) additionally contained CC instead of

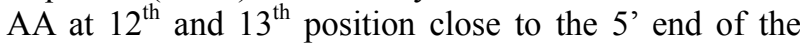
DNA molecule. Figure 6 presents the evident decrease of signal was observed when probe DNA was hybridized with two mismatches. It also can be seen that, the signal reduction of $\mathrm{mis} / 2$ was stronger than mis/1. From these results, it can be deduced that the electrochemical DNA sensor has enough high sensitivity to detect a single base pair mismatch DNA at some of positions within the sequence.

\subsection{Hybridization with PCR Amplified Sample}

The DNA sequence of herpes virus in real sample was used in our work. Firstly, the DNA sequences of herpes virus were amplified by PCR method $(20 \mu \mathrm{g} / \mu \mathrm{l})$ and then divided into 2 parts: $10 \mu \mathrm{g} / \mu \mathrm{l}$ DNA sequence for gel electrophoresis; $10 \mu \mathrm{g} / \mu \mathrm{l}$ DNA sequence for DNA hybridization detection using the DNA sensor. The Figure 7 showed results of 92 base pairs fragment-amplified by PCR method in which lance M indicates the Marker,

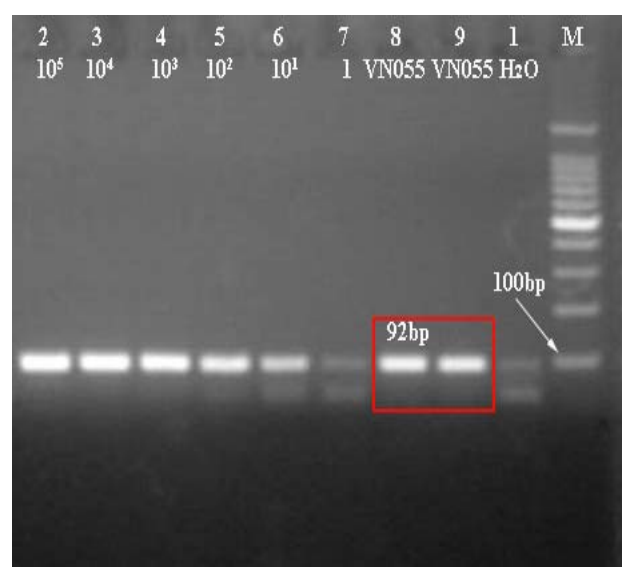

Figure 7. Agarose gel electrophoresis of the PCR products amplified in the thermal cycler.

Openly accessible at http://www.scirp.org/journal/JBISE/ 


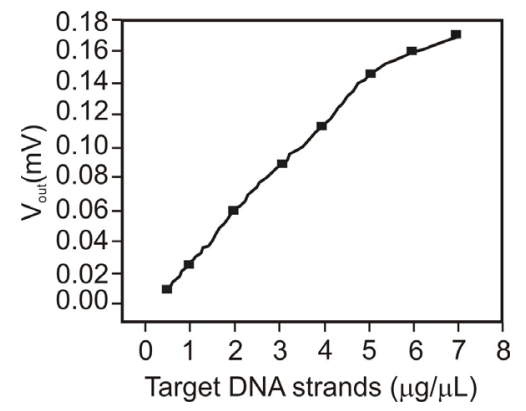

Figure 8. PCR amplified DNA sequence detected by DNA sensor.

lane 1: PCR performed in $\mathrm{H}_{2} \mathrm{O}$ Enppendorf tubes, lanes $2 \div 7$ : the DNA template with various DNA concentrations, and lanes 8, 9 are for the Herpes virus PCR products with 92 base pairs.

Note that, the PCR amplified sample was double strands, thus, before the performance of DNA sequence detection, the sample was thermally denatured at $98^{\circ} \mathrm{C}$ for 5 minutes and then was quickly decreased to $50^{\circ} \mathrm{C}$ to obtain the single DNA strand. Afterwards, our DNA sensors were immerged into the cell containing the sample to detect the target. Figure 8 described the relation between target DNA concentration and output signal of DNA sensor at room temperature, phosphate buffer solution with $0.5 \mu \mathrm{M}$ probe DNA. It can be seen that, output signal of DNA sensor is linear with target DNA concentration. This result went well that given by PCR method and matched our purpose to develop the DNA sensor as pre-diagnostic device.

\section{CONCLUSIONS}

This paper described the direct immobilization of DNA strand on the surface of sensor by electrochemical method. The DNA sensor was used to determine the Herpes simplex virus DNA in the sample. The results showed that, the DNA sensor can detect as small as 2 $\mathrm{nM}$ of herpes virus DNA concentration at room temperature and the intensity of the output signal is better than by using APTS attachment method. The influence of mismatch DNA was determined with decrease of $50 \%$ signal (mis/1) and 75\% signal (mis/2) compares to full matching at $12 \mathrm{nM}$ target DNA concentration. We still keep doing further research to verify selectivity and sensitivity of the sensors at different measuring conditions.

\section{ACKNOWLEDGEMENTS}

The work has been supported by Ministry of Education and Training under research project code B2008-01-175

\section{REFERENCES}

[1] K. Jalava, S. Nikkari, J. Jalava, E. Eerola, M. Skurnik, O.
Meurman, O. Ruuskanen, A. Alanen, E. Kotilainen, P. Toivanen, and P. Kotilainen, (2000) Direct amplification of rRNA genes in diagnosis of bacterial infections, J. of Clinical Microbiology, 38, 32-39.

[2] J. Wang, G. Rivas, C. Parrado, X. Cai, and M. N. Flair, (1997) Electrochemical biosensor for detecting DNA sequences from the pathogenic protozoan Cryptosporidium parvum, Talanta, 44, 2003-2010.

[3] M. Passamano and M. Pighini, (2006) QCM DNA- sensor for GMOs detection, Sensors and Actuators B, 118, 177-181.

[4] A. Rang, B. Linke, and B. Jansen, (2005) Detection of RNA variants transcribed from the transgene in Roundup ready soybean, Eur. Food Res. Tech., 220, 438-443.

[5] J. Wang, G. Rivas, X. Cai, E. Palecek, P. Nielsen, H. Shiraishi, N. Dontha, D. Luo, C. Parrado, M. Chicharro, P. A. M. Farias, F. S. Valera, D. H. Grant, M. Ozsoz, and M. N. Flair, (1997) DNA electrochemical biosensors for environmental monitoring, Analytical Chemical Act., 347, 1-8.

[6] Y. Lu, J. Liu, J. Li, P. J. Bruesehoff, C. M. B. Pavot, and A. K. Brown, (2003) New highly sensitive and selective catalytic DNA biosensors for metal Ions, Biosensors and Bioelectronics, 18, 529-540.

[7] P. Rossmanith, M. Krassnig, M. Wagner, and I. Hein, (2006) Detection of Listeria monocytogenes in food using a combined enrichment/real-time PCR method targeting the prfA gene, Research in Microbiology, 157, 763-771.

[8] K. E. Yoder and R. Fishel, (2006) PCR-based detection is unable to consistently distinguish HIV 1LTR circles, Journal of Virological Methods, 138, 201-206.

[9] B. D. Rio, A. G. Binetti, M. C. Martín, M. Fernández, A. H. Magadán, and M. A. Alvarez, (2007) Multiplex PCR for the detection and identification of dairy bacteriophages in milk, Food Microbiology, 24, 75-81.

[10] I. Mannelli, M. Minunni, S. Tombelli, and M. Mascini, (2003) Quartz crystal microbalance (QCM) affinity biosensor for genetically modified organisms (GMOs) detection, Biosensor and Bioelectronics, 18, 129-140.

[11] X. D. Zhou, L. J. Liu, M. Hu, L. L. Wang, and J. M. Hu, (2002) Detection of hepatitis B virus by piezoelectric biosensor, J. Pharm. and Biomed. Anal, 27, 341-345.

[12] R. Epstein, I. Biran, and D. R. Walt, (2002) Fluorescence- based nucleic acid detection and micro arrays, Anal. Chimica Acta., 469, 3-36.

[13] T. Jiang, M. Minunni, P. Wilson, J. Zhang, A. P. F. Turner, and M. Mascini, (2005) Detection of TP53 mutation using a portable surface plasmon resonance DNAbased biosensor, Biosensors and Bioelectronics, 20, 1939-1945

[14] K. Yamashita, Y. Yamaguchi, M. Miyazaki, H. Nakamura, H. Shimizu, and H. Maeda, (2004) Microfluidic system for DNA sequence detection, Chem. Eng. Journal, 101, 157-161.

[15] P. D. Thanh, M. A. Tuan, N. D. Chien, and C. Jean-Marc, (2004) Investigation on interferences of conductometric biosensor using tyrosinase enzyme, in Proc. 7th Vietnamese-German Seminar on Physics and Engineering, Vietnam, 158-161.

[16] J. Wang, M. Jiang, A. Fortes, and B. Mukherjee, (1999) New label-free DNA recognition based on doping nu- 
cleic-acid probes within conducting polymer films, Anal. Chim. Acta, 402, 7-12.

[17] H. A. Tajmir-Riahi, (2006) An overview of proteinDNA and protein-RNA interactions, J. of the Iranian Chem. Soc., 3, 297-304.

[18] Y. Zhou and Y. Li, (2004) Studies of interaction between poly (allylamine hydrochloride) and double helix DNA by spectral methods, Biophysical Chemistry, 107, 273-281.

[19] L. S. Andréa and O. A. S. Maria, (2007) Electrodeposi- tion of polypyrrole films on aluminum from tartrate aqueous solution, J. Braz. Chem. Soc., 18, 143-152.

[20] M. Omastová, J. Pionteck, and S. Koina, (1996) Preparation and characterization of electrically conductive polypropylene/polypyrrole composites, Eur. Polym. J., 32, 681- 689 .

[21] H. N. Cong, K. E. Abbassi, J. L. Gautier, and P. Chartier, (2005) Oxygen reduction on oxide/polypyrrole composite electrodes: effect of doping anions, Electrochimica Acta., 50, 136-1376. 